\title{
FOSTERING DESIGN LITERACY, EMPATHY AND AWARENESS IN CODESIGN
}

\author{
Andree WOODCOCK ${ }^{1}$, Tim BALL ${ }^{1}$, Katarzyna GUT ${ }^{2}$, Paul MAGEE ${ }^{3}$, Deana McDONAGH ${ }^{2}$, \\ Louise MOODY ${ }^{1}$, Felipe MOREIRA ${ }^{3}$ and Sinead OUILLON ${ }^{4}$ \\ ${ }^{1}$ Faculty of Arts and Humanities, Coventry University, United Kingdom \\ ${ }^{2}$ Future Transport and Cities Research Institute, Coventry University, United Kingdom \\ ${ }^{3}$ Faculty of Health and Life Sciences, Coventry University, United Kingdom \\ ${ }^{4}$ Centre for Trust, Peace and Social Relations, Coventry University, United Kingdom
}

\begin{abstract}
Using low fidelity simulations, the authors have previously introduced elements to an undergraduate product design module, to improve empathic forethought among student designers, designing with and for elders. Student feedback suggested a willingness and enthusiasm to adopt more empathic approaches to design problems and an understanding of the responsibility that resides in their hands. They also suggested that training could be enriched by engaging with elders during concept development and prototyping. In codesign, citizens may be asked to inform, constrain and evaluate product development to meet 'their' needs or those of their peers. It is often these insights which provide a basis for innovation around which designers can instil value, desire, benefit and affect perceptions of stigmatizing issues. Using a real-world scenario, students followed empathic, auto-ethnographic experiential learning exercises before engaging with elders.

Mindful of the need for such interactions to be enjoyable, fruitful, reliable and valid for both students and participants, this study focused on the interaction between students and elders during concept development and final presentation. Six groups (32 students in total) were observed interacting with 12 elder citizens. Data was gathered from students' reflections, observations of tutors, and focus groups with elder citizens. From this, we have developed guidelines to ensure that both citizens and students derive maximum benefit and enjoyment from these activities.
\end{abstract}

Keywords: Empathy, old age, experiential learning, codesign, mobility, ethics

\section{INTRODUCTION}

Empathy may be defined as 'the intuitive ability to identify with other people's thoughts and feelings their motivations, emotional and mental models, values, priorities, preferences, and inner conflicts' [1] and is based on a deeper understanding of the lived experience that is traditionally expected of design students. Student designers may have little experience designing for populations unlike themselves. This can present challenges when design briefs require solutions for people with different life experience and ability. Without understanding the real context of users' experience, resulting designs may fail to meet the needs of target users. Methods used to encourage empathy and ensure transformative learning have been iteratively developed by the authors particularly in relation to mobility challenges [2, 3, 4]. This approach has been explained in [3] but may be summarised as having two components:

1. Experiential, in which students conduct everyday tasks with reduced hearing, vision, dexterity and mobility and engage on campus tours in wheelchairs, on crutches, using walking frames and a gerontology suit (Figure 1).

2. Reflection in, on and through action [2], in which students are prompted to discuss what they found difficult or surprising, how they felt and how they could make use of the understanding and techniques in their design practice. 


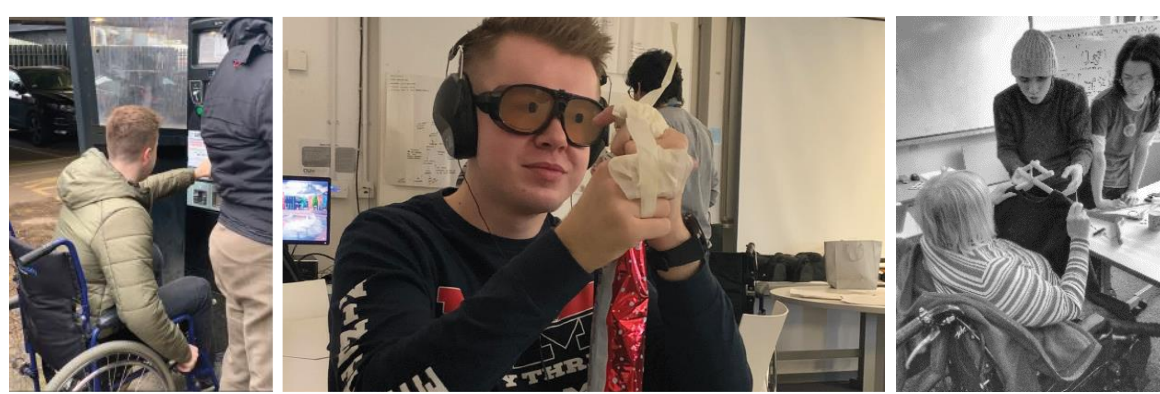

Figure 1. Examples of student empathic modelling (Photos courtesy of Maryniak, Priestley, Monkman, Shepherd and Launder, 2020) and codesign exercises

Our previous work has shown that even giving students a short period of time when they can experience limited mobility and sensory loss can lead to deeper thinking about, and empathy with, elders, enabling them to pass through an 'empathy threshold' [5], and transfer experiential knowledge into design concepts. However, students comment that they would value the opportunity of talking to older people about their designs.

This paper discusses how we responded to that challenge, creating a best practice framework for working with elders in university settings and in Coventry's living lab. This was one of the first opportunities for students to move from user centred design to codesigning, in which the person being designed for is seen as an expert in their own experience [6] and as vital to knowledge exchange, idea generation and concept resolution. Prior to inviting the elders into the class, all students undertook empathic modelling exercises and observations to establish some insights into age related physical and sensory issues.

In considering the learning experience and effective working practices we wanted to identify and investigate issues to be addressed to ensure that both parties (students and older people) gain value, enjoyment and satisfaction from a design collaboration; what facilitated or impeded the exchange of ideas, and how was the input from the elders treated? These are issues, both practical and ethical are often ignored in design research [7] but central to the philosophy of Living Labs and the ethos of cocreation [8]. We have begun to explore these elsewhere in the establishment of a Living Lab setting with elders and established researchers [8], but here the focus is on the interaction between elders and student designers whilst addressing a design brief.

\section{METHOD}

The starting point for the design was a real-world incident experienced by the lead author in which an older lady asked for her help in walking to a taxi rank. Although she had been out shopping with friends, this was her first solo outing following hip replacement surgery. She had not used any mobility aids due to the stigma associated with them. She was clearly exhausted and walking with a lot of pain. Handing over her bags and leaning on us for support required a lot of trust on her part.

In using this, students were asked to consider: What does the term 'mobility problem' mean? How do you know? What method can you use to look behind the words and find the real meaning? With such an emotive issue, what is your role in design? What will you do to ensure that you understand the needs of the user and not an interpretation of the situation based on your own life experience? Why? What guidelines could be put in place, as part of the hybrid role, that would enable this philosophical standpoint to become standard practice? Successfully addressing the design brief required students to learn from real world observations, be empathic active listeners, communicate and manage their teams. The project relied upon reflection and aim to develop the students understanding of aging. The aim was for each student to develop their felt sense into a felt experience.

The design challenge was run over 4-weeks (as shown in Table 1) involving 32 Product Design students (self-arranged into 6 groups). They engaged in timetabled activities, worked on design concepts and outputs with support from course tutors between sessions. After each major stage (3, 4, 6 and 8) they were required to complete guided self-reflection sheets. These, along with the observational records of the instructors and research team provided data from which guidelines were constructed. 
Table 1. Overview of stages, showing when feedback was given and collected

\begin{tabular}{|l|l|l|}
\hline \multicolumn{1}{|c|}{ Stage } & \multicolumn{1}{|c|}{ Design activities } & \multicolumn{1}{c|}{ Research outcomes } \\
\hline 1. Project introduction & $\begin{array}{l}\text { Lectures, expectations, } \\
\text { management of the challenge, } \\
\text { icebreaker }\end{array}$ & Mind-maps, pre- empathy quiz \\
\hline 2. Observations in city & Storyboards, personas & Group presentation \\
\hline $\begin{array}{l}\text { 3. Mobility restricted } \\
\text { walk round campus }\end{array}$ & $\begin{array}{l}\text { Gert suit, wheelchair, walking } \\
\text { frames, restricted vision, }\end{array}$ & Quick notes for guided student reflections \\
\hline $\begin{array}{l}\text { 4. Low fidelity } \\
\text { experiential simulations } \\
\text { in studio }\end{array}$ & $\begin{array}{l}\text { Simple tasks with restricted vision, } \\
\text { hearing, hand movements }\end{array}$ & Quick notes for guided student reflections \\
\hline $\begin{array}{l}\text { 5. Concept } \\
\text { development }\end{array}$ & $\begin{array}{l}\text { 2D flatwork and sketch models, } \\
\text { fishbowl feedback and tutorials }\end{array}$ & Tutor observations and reflections \\
\hline $\begin{array}{l}\text { 6. Codesign with elders } \\
\text { over 2 hours }\end{array}$ & $\begin{array}{l}\text { Presentation and discussion of } \\
\text { designs with drawings and models }\end{array}$ & $\begin{array}{l}\text { Quick notes for student reflections, tutor } \\
\text { observations and reflections }\end{array}$ \\
\hline $\begin{array}{l}\text { 7. Presentation } \\
\text { rehearsal }\end{array}$ & $\begin{array}{l}\text { Group presentations and feedback } \\
\text { on designs }\end{array}$ & Tutor and student reflections \\
\hline $\begin{array}{l}\text { 8. Final presentation } \\
\text { Group presentations and 'awards' }\end{array}$ & $\begin{array}{l}\text { Tutor observations and reflections; focus } \\
\text { group with elders; focus group with } \\
\text { students. Post empathy quiz }\end{array}$ \\
\hline
\end{tabular}

Around 12 elders participated in the co-design and feedback sessions (stages 6 and 8). Each session lasted around 3 hours (including introduction, refreshments and debriefing). Elders also selected which group they thought had developed the most useful and usable solution. They were given a token reward and refreshments for their participation. Not everyone was able to attend both sessions.

\section{DESIGN ACTIVITIES}

Each group decided how they would meet the brief and self-managed in-line with standard undergraduate design practice. This approach is not without its problems. In non-mandatory course elements (such as this), membership may become fluid and some students may not to fully participate. Also, different groups may answer the design brief in the same way, or in highly different ways, making comparisons and equivalence difficult.

After the low fidelity experiential simulations, the groups focused on their design directions (Table 2). All designs approached a real-world problem, based on group observations and their experiences of simulated limited mobility. Formal feedback was provided using fishbowl technique [9] tuned to their needs [10] and informal discussions in the design studio. Table 2 summarizes final design concepts.

The elders were invited into the design studio after an introductory lunch in which the project and their role in it was explained. A pair of elders worked with each group for around 40 minutes (or when conversations naturally came to an end) after which they moved to a second group. All groups received insight into ageing and comments on their design thinking from 4 people. Tutors made informal observations on each group about what went well and where difficulty occurred. Students also reflected on their experiences. All groups then had 1 week to develop designs in consultation with tutors.

After a 'dress rehearsal', each group presented their final designs to a panel of elders for 20 minutes (10 minutes presentation, 10 minutes question and answers). During this, they were expected to present their background research (e.g. observations; market research, personas, storyboards and mind-maps), concept development (sketches, prototype models) and final concepts. Each group was assessed in terms of overall quality of presentation, explanation of design, understanding of needs and requirements, novelty, perceived usefulness and usability. Tutors rated the groups in terms of teamwork, designs and extent to which they exhibited empathy in design. A prize was awarded to each winning group. The elders selected the collapsible walking stick with jointed ferrule; the tutors, the bench design (refer to Table 2). 


Taking the idea of trust through companionship the team developed a walking stick
with a GPS enabled discrete assistant. The system would communicate with the
user through vocal feedback, haptic response or text on a built-in display. The
premise being that elders of the future will be accustomed to integrated technology
and not threatened by it.

\section{RESULTS AND CONCLUSIONS}

Student feedback showed that they valued the simulation exercises which provided insights into how difficult even the simplest of tasks could be. Their increase in empathy was measured before and after the interventions using the Berkeley Empathy Quiz ${ }^{1}$ which showed a slight but non-significant increase in empathy. However, half the students completed both parts of the survey and the results do not correlate with the qualitative feedback. We acknowledge the wish to have more time and interaction with elders. As this was the first time, we had tried this, we considered that two 3-hour visits were the most we could expect. The study took place at the start of the spring term with recruitment in January. Their participation required travel to the university in wintry conditions. The design department is located close to the city-centre but not within walking distance for many of our guests. Access to elders is a valuable resource to any design students yet all the participation overheads are placed on the elders. We therefore wanted to learn how these interactions could be optimized.

The lack of motivation from some students led to issues with group cohesion and poorly resolved designs. This could have impacted on the co-design sessions. Students reflected that their groups were too large and that they had been constrained by the problem-led design brief. They suggested that their discussion with elders should have taken place earlier, before observations and empathic modelling should have taken place after their talks with their 'co-design session', which perhaps misses the point.

'It would have been more beneficial to have the meeting with the elders before the lo-fi and GERT suit simulations, as less assumptions would have been made', and 'Even if we did those observations... they were more like our speculations. If we could meet elderly at the beginning and just ask them directly would have been more factual rather than just making assumptions.' Student focus group.

\footnotetext{
${ }^{1}$ https://greatergood.berkeley.edu/quizzes/take_quiz/empathy
} 
Our visitors expressed real enjoyment with both sessions, asking for more opportunities to become involved with student projects and setting design challenges. Feedback was overwhelmingly positive and supportive. This alleviated some of our original concerns.

'Surprisingly enough I did feel quite confident, but I think it was response that was coming to me. I mean...they were asking and listening about number of things... I mean the interaction in two groups I was in was fantastic. 'Elder, P1.

They would also have liked longer and more detailed conversation with the students and to share more about their lives, as they felt that the students were sometimes operating under misconceptions.

'Both of the groups I was working with last week said to me they wished they had had this session before they started. One of the groups said they wasted their time and they needed to go back to square one...... I think we should come here from the very beginning. 'Elder,

P.1 'Yes, would be good to have more sessions. It just seemed a little bit rushed.' Elder, P5.

Elders were generous with insights into their lives and offered pertinent feedback on concept designs.

'We were saying things about our bags that this is a real problem and one of the groups changed their design and had the nerve to go and do something else. That's really great.' Elder, P4.

Conversely students were more critical of the interactions, commenting that elders took too egocentric an approach. This may indicate that more direction was needed. Analysis of the feedback using breakdown analysis has led to the development of guidelines for students, elders and managers of codesign activities to ensure maximum benefit is derived by both groups from such session. These will form the basis of protocols for the design department and our 10 TInnGO European hubs, conducted along Living Lab principles, in which citizens will be invited to collaborate with designers and transport planners to create gender and diversity sensitive smart mobility solutions. The guidelines for students relate to codesign recommendations and audience-centred presentations.

\section{Co-design recommendations for students included the need to:}

1. Prepare the room and the session, including how the team and the focus is introduced, and what is expected during codesign. making sure everyone can see and hear what is going on

2. Take control and set boundaries for engagement, so that discussion is focused and to the point.

3. Establish a 'multi/logue'/'log' where everyone participates, offers ideas and is welcomed to do so.

4. Plan recording of notes and check that these inform decisions.

5. Create sketch models and drawings to communicate ideas and have a lot of material available for modelling

6. Be active listeners

7. Understand that choices about project direction are not based on personal preference or sense of style - instead, accept that decision is based upon validation by the representative demographic.

Regarding the development of audience-centred presentations, students should:

1. Create a narrative arc around key features of the design and consider the impact.

2. Understand the room and the audience e.g. acoustics, lighting, seating, use empathic presentation skills judiciously using fonts and contrasts, especially for elders who may have visual and hearing impairment.

3. Experiment with different forms of presentation, creating a sense of theatre and occasion e.g. through use of models, handouts and appropriate humour.

4. Consider how the group is presented, be respectful and mindful of each other, listen to feedback and take notes, engage in eye contact and active listening, and using the right language, avoiding terms which may be patronising, ambiguous or contradictory.

5. Rehearse so that everyone knows the narrative of the presentation, their role and timings.

Advice for those running sessions (taken from feedback from elders and students):

1. Earlier and more prolonged engagement, providing a memento for closure follow ups.

2. Provide opportunities for further engagement to keep interest and involvement of elders.

3. Design a time and space for engagement bearing in mind accessibility to build on opportunities for longer and more detailed discussion.

4. Try to have wide gender and ethnic diversity

5. Let the elders choose/identify themes and challenges they are interested in, have experience of and those relevant to their life-stage needs and aspirations.

6. Build up a repository of projects for benchmarking and contextualizing learning 
Advice for elders engaged in codesign (taken from student reflection). The recommendations were that elders should be guided / encouraged to:

1. Represent a specific demographic, not just themselves.

2. Objectively look at the product from the perspective of a potential buyer or user.

3. Not let their own bias or dislike of a product effect their comments.

4. Understand that their valuable participation was to improve to products and help the students learn. To conclude; while empathic modelling takes the student outside their comfort zone it enables them to identify opportunities for design solutions to enhance the quality of life for others, and possibly their future selves. As a result of this design project students have been able to develop and test co-design skills and understand both the process and potential challenges of working with elders during the design process. The recommendations add to a growing body of research interested in how best to collaborate with elders and ensure their experiences and needs are represented in new product development.

\section{ACKNOWLEDGEMENTS}

Supported in part by H2020 TInnGO project and the Frank Jackson Foundation, UK grant making Trust which supports education for the disadvantaged and world class research in institutions of higher learning. Special thanks to $2^{\text {nd }}$ year Product Design staff and students at Coventry University, UK.

\section{REFERENCES}

[1] Woodcock A, McDonagh D and Osmond J. Developing Empathy for Older Users in Undergraduate Design Students. Design and Technology Education Journal, 23(2): 24-39, 2018.

[2] Schön D. A. Educating the reflective practitioner: Toward a new design for teaching and learning in the professions, 1987 (Jossey-Bass. San Francisco, CA, US).

[3] Woodcock A., McDonagh D., Magee P., Ball T. and Iqbal, S. Expanding horizons: Engaging students with empathic thinking. In E. Bohemia, et al (Eds.), Proceedings of the 21st International Conference on Engineering and Product Design Education: Towards a New Innovation Landscape, E and PDE 2019. IED, The Design Society.

[4] Moody, L., Mackie, E. and Davies, S. 'Building Empathy with the User' in Karwowski W., Soares M., Stanton NA. (ed.) Handbook of Human Factors and Ergonomics in Consumer Product Design. 2011. CRC Press ISBN 9781420046250

[5] Osmond J., Woodcock A., Tovey M. and McDonagh D. Empathy thresholds in transport design students, Design and Technology Education Journal, 2019.

[6 Sanders E.B.-N. and Stappers P.J. Co-creation and the new landscapes of design, CoDesign, 4:1, 5-18, 2008.

[7] Woodcock A., McDonagh D., Kaur, K., Ouillon, S. and Nainby P.C. Empowering Seniors to Discuss Transport Provision to Health Services OpenLivingLab Days 2016.

[8] Callari T. C., Moody L., Saunders J., Ward G. and Woodley J. Stakeholder Requirements for an Ethical Framework to Sustain multiple research projects in an Emerging Living Lab Involving Older Adults, Journal of Empirical Research on Human Research Ethics, 1-17, 2019.

[9] Fruchter R. The Fishbowl: Degrees of Engagement in Global Teamwork. In: Smith I.F.C. (eds.) Intelligent Computing in Engineering and Architecture. EG-ICE. Lecture Notes in Computer Science, vol 4200. (Berlin, Heidelberg Springer), 2006.

[10] CCW, 2019. Co Creating Welfare. www.ccw.eu (accessed $6^{\text {th }}$ January 2020). 